\title{
The permeability transition pore in cell death
}

\author{
Stefan Grimm • Dieter Brdiczka
}

Published online: 15 February 2007

C Springer Science + Business Media, LLC 2007

\begin{abstract}
The permeability transition pore (PT-pore) is a multi-component protein aggregate in mitochondria that comprises factors in the inner as well as in the outer mitochondrial membrane. This complex has two functions: firstly, it regulates the integration of oxidative phosphorylation into the cellular energy household and secondly, it induces cell death when converted into an unspecific channel. The latter causes a collapse of the mitochondrial membrane potential and activates a chain of events that culminate in the demise of the cell. It has been controversial for some time whether the PT-pore is causative for or only amplifies a signal of cell death but novel results confirm a central role of this protein complex for cell death induction. While a considerable body of data exist on its subunit composition, recent genetic knock-out experiments suggest that the identity of the core factors of the PT-pore is still unresolved. Moreover, accumulating evidence point to a much more complex composition of this protein complex than anticipated. Here, we review the current knowledge of its subunit composition, the evidence of a role in cell death, and we propose a model for the activation of the PT-pore for cell death.
\end{abstract}

Keywords Apoptosis · Mitochondria · Phospholipids · Cardiolipin $\cdot$ Contact sites $\cdot$ Membrane structure

\footnotetext{
S. Grimm $(\bowtie)$

Imperial College London,

Hammersmith Campus, Du Cane Road,

London W12 0NN, UK

e-mail: s.grimm@imperial.ac.uk

D. Brdiczka

University of Konstanz, Faculty of Biology,

Universitätsstraße 10,

78464 Konstanz, Germany

e-mail: dieter.brdiczka@uni-konstanz.de
}

\section{The role of the PT-pore in apoptosis}

\section{The permeability transition}

The permeability transition (PT) is a sudden and sustained increase of the permeability of the inner mitochondrial membrane for solutes smaller than $1.5 \mathrm{kD}$. This has catastrophic consequences for this organelle. The mitochondrial membrane potential $\Delta \Psi_{\mathrm{m}}$, which relies on the im-permeability of the inner membrane for protons, breaks down and with it the ability of the cell to synthesize ATP. The ensuing blockade of the respiratory chain leads to the generation of reactive oxygen intermediates (ROIs), most likely via the direct transfer of electrons to molecular oxygen. Also, the high concentration of solutes in the mitochondrial matrix generates an osmotic pressure, which drives the influx of water molecules and the expansion of the extensively folded inner membrane and eventually disrupts the outer membrane leading to the release of factors that execute the suicide programme of apoptosis. Thus, the self-destruction of mitochondria via the PT is followed by the demise of the cell as a whole. This process of mitochondrial destruction was first observed in vitro but was dismissed at the time as an artefact because, among other reasons, it was inconceivable why mitochondria should dispose of a process to dismantle themselves. This changed, however, when it was shown that the PT is mediated by a protein complex, the so-called permeability transition pore (PT-pore), and that various physiological and pharmacological reagents can act on this pore and modify the deadly response of mitochondria. Finally, the realisation that cells can mount an active suicide response that is mediated in large part by mitochondria placed the PT-pore firmly on the map of researchers. In particular, the use of cyclosporine A (CsA) that can inhibit the PT-pore subunit cyclophilin $\mathrm{D}$ and also reduces cell death in many scenarios played 
a crucial role to establish the importance of the PT-pore [1].

\section{Evidence for a role of the PT-pore in apoptosis}

The respiratory chain generates a proton gradient over the inner mitochondrial membrane. This membrane potential $\Delta \Psi_{\mathrm{m}}$ is the driving force for oxidative phosphorylation. The original observation that implicated the PT-pore in apoptosis was the discovery that many cell death signals lead to the dissipation of $\Delta \Psi_{\mathrm{m}}$ before other morphological signs can be detected. This precedes, for example, the exposure of phosphatidylserine, major changes in cellular redox potentials [2], and nuclear events in apoptosis such as the degradation of genomic DNA [3]. In fact, the breakdown of this proton gradient seems to be a better cell death predicator than the activation of caspases, since these cystein proteases can be activated without the subsequent demise of the cells provided that $\Delta \Psi_{\mathrm{m}}$ is kept intact $[4,5]$. Also, in some models of apoptosis caspase or nuclease activation does not occur but $\Delta \Psi_{\mathrm{m}}$ dissipation is nevertheless observed [6, 7]. However, as a cautionary note we have to stress that this does not suggest that in each case the PT-pore is responsible for $\Delta \Psi_{\mathrm{m}}$ dissipation as it is possible that factors other than the PT-pore are involved [8]. Moreover, some techniques used for the measurement of $\Delta \Psi_{\mathrm{m}}$ are complicated by problems such as toxicity of the probes, concentration dependent quenching or inhibition of the respiratory chain [9]. Nevertheless, there is now extensive and solid evidence that the PT-pore is involved in many scenarios of cell death. Importantly, a number of positive and negative modulators of the PT-pore also regulate cell death. The PT-pore ligands bongkrekic acid and the already mentioned CsA, for example, inhibit cell death, whereas atractycloside favours apoptosis. Moreover, the apoptosis regulators of the Bcl-2 family also modulate the PT-pore. Bax can lead to $\Delta \Psi_{\mathrm{m}}$ dissipation in some cells that is CsA inhibitable [10-12] and the anti-apoptotic Bcl-2 can prevent $\Delta \Psi_{\mathrm{m}}$ collapse in isolated mitochondria and apoptosis in intact cells [13].

Hence, based on these results and many biochemical in vitro studies [14] the prevailing theory stipulates that the PT-pore is, upon suitable stimulation, converted into an unspecific channel and leads to PT and the biochemical and cellular consequences elaborated above. In this standard model the PT-pore subunit adenine-nucleotide-translocator (ANT) (see below) in the inner mitochondrial membrane can adopt different conformations that are distinguished by their propensity to be turned into an unspecific channel for PT. The c-conformation of ANT, which is stabilised by the compound atracyloside, is more prone to form the unspecific pore, whereas the m-conformation, which is adopted upon binding to bongkrekic acid, is refractory to form a channel.
The original and still most prominent inducers of the PTpore are oxidative stress and increased $\mathrm{Ca}^{2+}$ levels. Both stimuli are generated by a wide variety of cell death signals thereby providing a rational for the frequent involvement of the PT-pore in cell death. Superoxide, for example, is formed by $\mathrm{Ca}^{2+}$ dependent stimulation of substrate supply for the respiratory chain and a lack of ADP (see Fig. 2). These ROIs can further activate the PT-pore and establish a feed forward amplification loop. Exactly how the stimuli, oxidative stress and increased $\mathrm{Ca}^{2+}$, activate the PT-pore is not known. It has been suggested that $\mathrm{Ca}^{2+}$ binds to the negatively charged cardiolipin head in the inner membrane, which affects ANT that is associated with this lipid [15]. This would facilitate the conversion of ANT into a conformation that can be turned into an unspecific channel. Other theories suggest a direct binding of $\mathrm{Ca}^{2+}$ to ANT and the subsequent switch to an unspecific channel [14]. Oxidative stress is also supposed to act directly on ANT. Two thiol groups in cysteins are implicated in redox reactions that, like $\mathrm{Ca}^{2+}$ binding, change the conformation of the ANT transporter [14].

\section{Evidence against the PT-pore in cell death and modifications of the standard model}

Despite all the data implicating the PT-pore in cell death, a number of caveats have been raised against the PT-pore: Some investigators failed to see a dependence on the PT-pore for Bax- and Bid- induced apoptosis [16-19]. Also, in some apoptosis scenarios Bax-induced release of cytochrome $c$ could not be inhibited by bongkrekic acid and or CsA [20]. Of note, while both Bax and t-Bid bind to cardiolipin in the contact sites, they have different modes of action. t-Bid incorporates into the inner membrane causing a redistribution of cytochrome $c$ [21], and Bax releases cytochrome $c$ directly from its binding sites. Bax/Bak oligomerisation thus seems to be in some cell death scenarios a more decisive step for apoptosis induction than the activation of the PT-pore. Also, the swelling of the inner mitochondrial membrane as proposed in the standard model of PT-pore activation is not observed in all scenarios of apoptosis [22]. Moreover, the permeabilisation of the inner membrane is sometimes seen later during apoptosis induction, after the release of cytochrome $c$ and caspase activation, and was therefore suggested to be a consequence rather than the cause of apoptosis induction [23-26]. Hence, it had been proposed that the PT-pore only serves as an amplifier of a cell death signal rather than the cause of the demise of the cell.

Based on these criticisms a number of refinements and alternatives to the standard model of PT-pore activation have been brought forward. It was proposed, for example, that PT-pore-dependent and -independent mechanisms for outer membrane permeabilisation exist, possibly in a cell type- and signal-specific manner. Nerve growth factor withdrawal 
in sympathic neurons, for example, causes cytochrome $c$ to be released from mitochondria in a Bax-dependent but PT-independent fashion. This leads to the activation of caspases, which impact on the PT-pore, cause PT and overt cell death. If caspases are inhibited the cell is kept alive until $\Delta \Psi_{\mathrm{m}}$ drops [27]. In fact, in many cases caspases can activate the PT-pore [28, 29] and caspase inhibitors consistently inhibit the dissipation of $\Delta \Psi_{\mathrm{m}}[18,26]$. This indicates that, while the PT-pore is downstream of cytochrome $c$ release and caspase activation in some experimental settings, the PT still constitutes the point of no return [27].

Also, it has been suggested that the PT-pore temporarily opens ("flickers") leading to only a transient $\Delta \Psi_{\mathrm{m}}$ collapse [30]. However, this suffices to render the outer membrane permeable for apoptosis factors. Elegant experiments, for example, showed that an increase in mitochondrial $\mathrm{Ca}^{2+}$ can induce further $\mathrm{Ca}^{2+}$ release [31] (which is suppressed by ADP provided by mitochondrial kinases [32], see Fig. 2). Hence, high $\mathrm{Ca}^{2+}$ or a combination of other signals might act on the PT-pore and lead to a transient collapse of $\Delta \Psi_{\mathrm{m}}$, cytochrome $c$ release, a resealing of the inner membrane, and a restoration of $\Delta \Psi_{\mathrm{m}}$. While the cells finally undergo apoptosis, this could explain why no overt collapse of $\Delta \Psi_{\mathrm{m}}$ is seen in many instances of apoptosis.

Alternatively, the small perturbation caused by a transient opening of the PT-pore can result in the activation of stress signalling pathways such as the activation of Bax [33], which ultimately causes outer membrane disruption and cytochrome $c$ release. Hence, the complete loss of the mitochondrial membrane potential could only be the end stage of the dismantling of the cell.

Some experiments suggest that the PT-pore could induce a structural rearrangement of the cristae and recruit cytochrome $c$ for release from mitochondria [33]. Alterations in cristae morphology and cytochrome $c$ loss can be inhibited by the PT-pore inhibitor CsA, which indicates that a structural change in the PT-pore complex is responsible for the release of specific pro-apoptotic factor for apoptosis induction. Thus, it might not be necessary to open the PT-pore as in the standard model but just to change the structure of the PT-pore complex and the distribution of its components. A typical example is the action of the ANT ligands bonkgrekic acid and atractyloside. Bonkgrekic acid inhibits cell death, because through interaction with ANT it decreases the cytochrome $c$ concentration and presumably that of cardiolipin at the mitochondrial periphery. In constrast atractycloside supports apoptosis as its interaction with ANT causes an increase of the peripheral cytochrome $c$ concentration [85].

In conclusion, there is ample evidence for a role of the PT-pore complex in cell death and some modifications of the former standard model of PT-pore activation allow integrate all available data.

\section{The PT-pore in necrosis}

Necrosis and apoptosis are two fundamentally different forms of cell death. Morphologically, apoptosis is characterised by a shrinkage of the cells with their membranes intact, membrane blebbing and rapid phagocytosis of the dead cells, whereas during necrosis the plasma membranes disrupt and release cellular components in the extracellular space leading to an inflammatory response. While apoptosis is regulated by a genetic programme and requires an active contribution of the cell, necosis is the passive cell death that is (at least in most cases) independent of an underlying genetic programme. Comprehensive tests have yielded that the ATP level determines the way how the cells die with sustained ATP favouring apoptosis and a decreased ATP causing necrosis [34]. Since the PT-pore activation causes $\Delta \Psi_{\mathrm{m}}$ loss and a reduction of ATP it is surprising that this could contribute to apoptosis rather than necrosis. Thus, the transient nature of the PT-pore opening as proposed in one of the novel models (see above) could sustain the ATP level that is required for efficient execution of the programme of apoptosis.

Nevertheless, necrosis induction by the PT-pore has been described. A particularly well documented case is ischaemia/reperfusion injury of the heart [35]. While ischaemia, the lack of oxygen supply to tissues, does not lead to cell death, it is the subsequent reperfusion of the cells with oxygen and the oxidative stress that cause the demise of the cells. It seems that ischaemia initiates changes in the cells, such as the increase of free ADP, $P_{\mathrm{i}}$ and of cytosolic $\mathrm{Ca}^{2+}$. A disparity of high intra-mitochondrial substrate supply for the respiratory chain versus low ADP leads to superoxide production, which causes oxidative stress during reperfusion $[36,37]$. Such a scenario would lead to a vicious circle: the subsequent PT-pore opening would increase free ADP. This would further deregulate $\mathrm{Ca}^{2+}$ and curb the activity of oxidative phosphorylation resulting in further ROI production and PT-pore opening. Since the postulation of a role for the PT-pore in ischaemia/reperfusion numerous experimental evidence have been found supporting this. CsA, for example, the classical inhibitor of the PT-pore, could reduce PT in cardiomyocytes subjected to anoxia-reperfusion. Also, it protected against loss of $\Delta \Psi_{\mathrm{m}}$ and, importantly, against cell death [36]. Another example of the PT-pore in necrosis can be found in primary brain cells. Also in this system necrosis was only observed when the feed forward cycle of ROI formation and PT-pore activation mentioned above was initiated [38].

Several authors also proposed that the intensity of the insult and the duration of PT-pore opening could determine the mode of cell death. This is in line with the observation that only the cells surrounding a myocardial infarct site, which experience a less pronounced and shorter insult 
undergo apoptosis while those cells that are more severely affected die by necosis [39].

The core components of the PT-pore

On a molecular basis the PT-pore comprises the voltagedependent-anion-channel (VDAC), an unspecific pore protein, which is also called mitochondrial porin [40, 41], in the outer mitochondrial membrane and the adenine-nucleotidetranslocator (ANT), a specific ATP/ADP transporter, in the inner mitochondrial membrane. Directly associated with ANT in the matrix of mitochondria, is cyclophilin $\mathrm{D}$ (cypD), a chaperone with peptidylprolyl isomerase (PPIase) activity [42]. With the identification of VDAC as a subunit of the PTpore it became necessary to propose that the PT-pore exists in contact points of the peripheral inner with the outer mitochondrial membrane. This model of the PT pore is supported by a combination of biochemical and pharmacological data (see below).

\section{VDAC at the outer mitochondrial membrane}

Many indications exist that VDAC is a component of the PTpore. As with ANT its reconstitution into liposomes generated a complex resembling the PT-pore and specific ligands of VDAC such as Königs's polyanion inhibit the PT-pore [43]. Moreover, fractionating mitochondrial membranes led to the identification of complexes that contained VDAC, ANT and cypD and that behaved in an identical manner compared to the endogenous PT-pore [44]. The assumptions about VDAC structure are, in the absence of a crystal structure, derived from the known structure of bacterial porins [41] to which VDAC is related. Mammalian VDAC is a 31-kDa protein with stretches of alternating hydrophobic and hydrophilic amino acids that form a trans-membrane $\beta$-barrel composed of a single $\alpha$-helix at the $\mathrm{N}$-terminus and several trans-membrane amphipathic $\beta$-strands. According to different models the $\alpha$-helix at the $\mathrm{N}$-terminus protrudes outside [45], crosses the membrane [46] or interacts with the membrane or membrane proteins [47]. Computer modeling of VDAC's primary amino acid sequence has led to the development of models showing the trans-membrane organization, consisting of a single $\alpha$-helix and 13-, 16- or 19-transbilayer $\beta$-strands. These $\beta$-strands are connected by several peptide loops of different sizes on both sides of the membrane that serve as potential protein interacting sites [48-50]. It has been proposed that monomeric VDAC reconstituted in artificial membranes can serve as the functional channel [51]. However, evidence consistent with oligomerization of purified VDAC from rat liver or Neurospora crassa, and in yeast outer membrane suggests that VDAC forms dimers $[52,53]$ and possibly tetramers. In brain mitochondria [54] or recombinant human VDAC [55], the existence of VDAC dimers and tetramers in mitochondria has been reported. Thus, it has recently been proposed that VDAC oligomerization functions in mitochondria-mediated apoptosis [54, 55].

\section{The role of VDAC in controlling the interaction of mitochondria with the cytosol}

For a thorough understanding of the function of VDAC it is informative to recapitulate the evolutionary origin of the PT-pore. The original ATP providing system of the cell was anaerobic glycolysis ending with lactate production. According to the endosymbiont hypothesis [56], a second ATP energy providing system was acquired, the oxygen-dependent phosphorylation. In order to integrate the latter into the energy metabolism and convert the former bacteria into mitochondria the cell had to overcome difficult tasks. It had to keep the two compartments, cytosol and inner membrane matrix, separated, but also had to allow metabolite exchange. The metabolic partition is necessary because ATP synthesis in the two compartments has opposite prerequisites: firstly, while ATP synthesis through glycolysis depends on a high $\mathrm{NAD} / \mathrm{NADH}$ quotient (700) in the cytosol the opposite is true for oxidative phosphorylation (NAD/NADH quotient is 7 in mitochondria) [57]; secondly, energy consuming systems, for example ion pumps and actomyosin ATPase, depend on high free energy $\Delta G$ of the phosphoryl group transfer from ATP. To provide a $\Delta G$ of $59 \mathrm{KJ}$ per mol the ATP/ADP quotient has to be approximately 800 in the cytosol whereas it is about 5 in the mitochondria in order to support ATP synthesis [58, 59] (see Fig. 1). The hydrogen from cytosolic NADH is shuttled to the mitochondrial NADH oxidase as glycerol-phosphate or malate through the glutamate aspartate shuttle. However, a direct electron transfer exists to cytochrome oxidase from rotenone-insensitive outer membrane NADH oxidase via cytochrome b5 involving cytochrome $c$ and bypassing complex III [60]. The direct electron transfer by cytochrome $c$ depends on the existence of contact sites [61]. As shown in Fig. 1 a chain of cytochrome $c$ molecules might be involved to channel electrons to cytochrome a/a3. For ATP exchange the smart mechanism is not to export the mitochondrial ATP but just transfer the phosphoryl group from ATP to either glucose or creatine. This phosphoryl group transfer is performed by conversion of ANT from an unspecific uni-porter pore into an anti-porter specific for ATP and ADP and coupling of either hexokinase or creatine kinase to it (see Fig. 1) [62]. The transfer of the phosphoryl group to phosphor creatine serves to conserve a high $\Delta G$.

The voltage dependent anion channel (VDAC), [63] is the major transport protein in the outer mitochondrial membrane. As depicted in Fig. 1 the same isotype I of VDAC present in the outer mitochondrial membrane is also a component of the cell plasma membrane [47]. According to the 


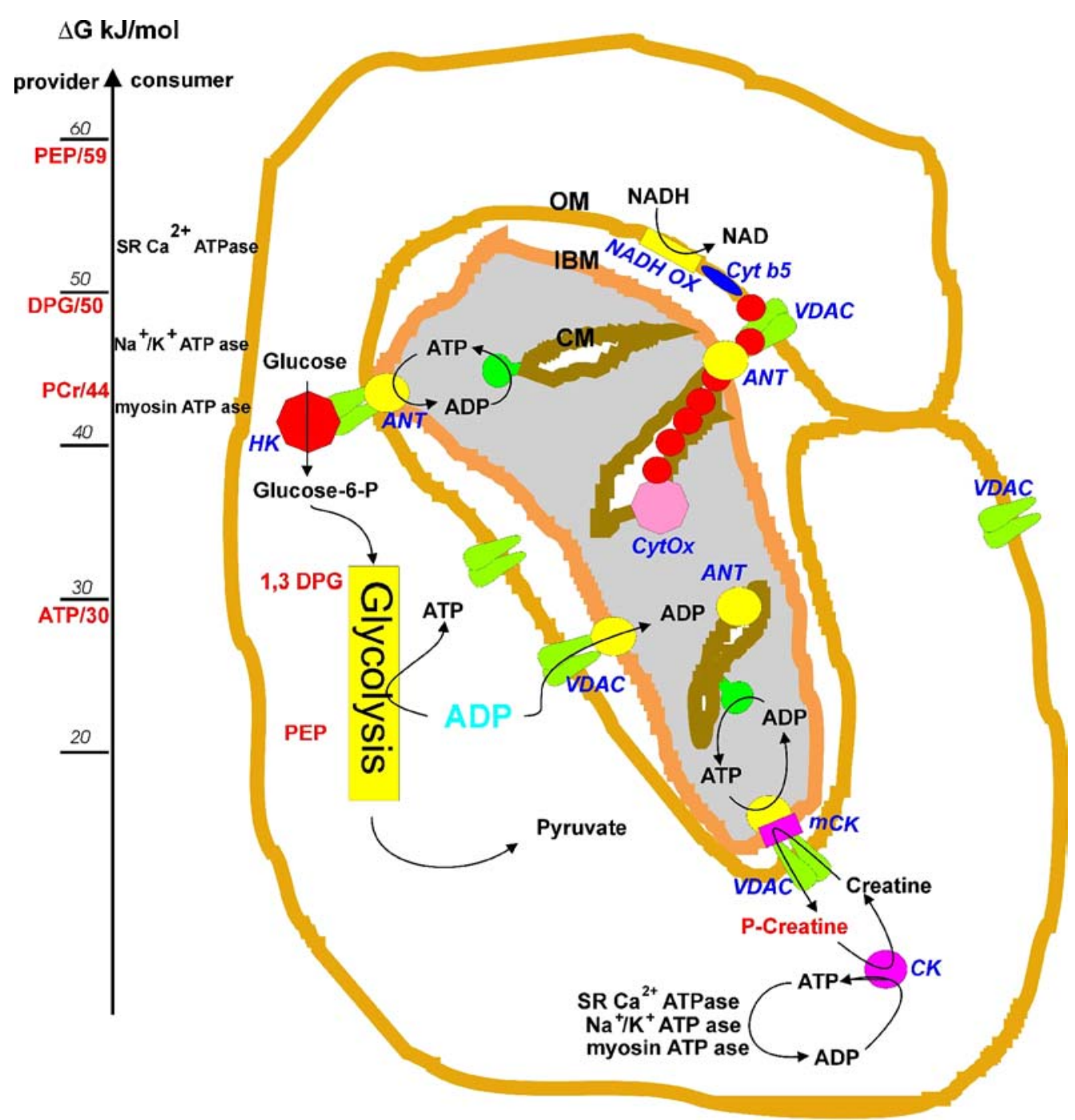

Fig. 1 Biochemical consequences of the origin of mitochondria as an endosymbiont. The mitochondrial outer membrane (OM) originates from the cell membrane and contains the same VDAC isotype I. The peripheral inner membrane (inner boundary membrane IBM) has the specific function to interact with the outer membrane, while the cristae membrane $(\mathrm{CM})$ has no contact with the OM. VDAC regulates the integration of glycolysis and oxidative phosphorylation by forming complexes with the adenine nucleotide translocator (ANT), hexokinase and creatine kinase. The hexokinase (HK)-VDAC-ANT complex has the function to adapt glucose phosphorylation and rate of glycolysis to intra-mitochondrial ATP synthesis. The VDAC-creatine kinase (mCK)-

aforementioned endo-symbiont hypothesis the incorporated bacteria (mitochondria) can still be considered as extracellular with the outer mitochondrial membrane providing a barrier between the mitochondrial inner-membrane matrix and the cell cytosol, and in this membrane VDAC mediates the complex interactions between mitochondria and other parts of the cell by transporting anions, cations, ATP, $\mathrm{Ca}^{2+}$ and metabolites. Thus, VDAC plays an important role in coordinating the communication between mitochondria and cytosol. An essential aspect of this management is
ANT complex has the function to increase the high free energy $\Delta G$ of phosphoryl group transfer of the ATP. On the left side the standard $\Delta G$ in $\mathrm{kJ} / \mathrm{mol}$ is shown for phosphor-enol pyruvate (PEP $59 \mathrm{~kJ} / \mathrm{mol}$ ) diphospho glycerate (DPG $50 \mathrm{~kJ} / \mathrm{mol}$ ) and phopho-creatine (PCr 44 $\mathrm{kJ} / \mathrm{mol}$ ). The standard $\Delta G$ is compared with the energy consumption of the SR $\mathrm{Ca}^{2+}$ pump $52 \mathrm{~kJ} / \mathrm{mol}, \mathrm{Na}^{+} / \mathrm{K}^{+}$ATPase $48 \mathrm{~kJ}$ and acto-myosine ATP ase $43 \mathrm{~kJ} / \mathrm{mol}$. On the right side the direct NADH oxidation pathway is shown involving outer membrane rotenone insensitive NADH oxidase, cytochrome b5 and cytochrome $c$, which transfers electrons to cytochrome oxidase and bypasses complex III

the transient formation of complexes of VDAC with other proteins (see below).

\section{ANT and cypD at the inner mitochondrial membrane}

ANT is a member of the superfamily of membrane transporters. Six membrane-spanning domains of 18-22 residues are separated by hydrophilic domains facing either the mitochondrial matrix or the intermembrane space. According to this model the $\mathrm{C}$ - and the $\mathrm{N}$-terminus protrude 
into the intermembrane space [14]. Biochemical isolations and reconstitutions in liposomes of the PT-pore suggested that those protein complexes consist of ANT in the inner membrane and VDAC in the outer membrane. These aggregates display a striking voltage dependence with gating effects that are consistent with the voltage dependence in intact mitochondria [15]. Moreover, reconstituted ANT facilitated malate transport that was inhibitable by the same reagents as the mitochondrial PT-pore [64]. As mentioned above the use of the immunosuppressant CsA marked an important advance of the field in that it showed that the PT can be inhibited by specific ligands. CypD has since been shown to be the target of CsA. It interacts directly with ANT $[65,66]$ and a cypD affinity matrix isolated ANT and VDAC and the reconstituted complexes mimicked a PT-pore [65]. CypD is a soluble protein in the mitochondrial matrix. Its crystal structure shows that it shares a common protein structure with other cyclophilins as expected based on the similarity of their primary sequences [67]. A $\beta$-barrel flanked by two $\alpha$-helices is formed by ten anti-paralell $\beta$-sheets, which are connected by loops of varying length.

\section{Accessory PT-pore subunits}

In addition to the classical components of the PT-pore enumerated above, which are supposed to constitute the core of the PT-pore, a number of accessory proteins have been detected associated with the PT-pore such as hexokinase I and II (HK) shown in Fig. 2. This protein interacts directly with VDAC in the outer membrane of mitochondria. Its displacement from VDAC is necessary for Bax binding and cell death induction. Hence, Bax as well as other Bcl-2 family members can, depending of the physiological state of the cell, interact with PT-pore components in the outer mitochondrial membrane. This is also the locale of the peripheral benzodiazepine receptor (PBR), an evolutionary conserved, $18 \mathrm{kD}$ protein with five membrane spanning domains that is characterised by its high affinity binding of a number of pharmacologically important substances. Mitochondrial creatine kinase (mCK) is found in the inter-membrane space of mitochondria and associates with ANT-1 at the contact sites (PT-pore) but also in the cristae with ANT-II (Fig. 2) [68]. New data also indicate that cytochrome $c$, a pivotal apoptosis inducer, is associated with the PT-pore. Moreover, specific lipids interact with components of the PT-pore and thereby modulate the activity of this protein aggregate (see below).

The role of VDAC in organizing kinases at the mitochondrial surface

Hexokinase $[69,70]$ and the octamer of mitochondrial creatine kinase [71] bind specifically to VDAC. The coupling of hexokinase to the mitochondrial ATP by the VDAC-ANT complex has the function to regulate the rate of glycolysis by glucose phosphorylation according to the activity of mitochondrial oxidative phosphorylation (Fig. 1). While in neurons this coupling is permanent through hexokinase I it varies depending on the cytosolic $\mathrm{Ca}^{2+}$ level in muscle because hexokinase II is missing the hydrophobic anchor [72] and is therefore only transiently interacting with the PT-pore. The coupling of VDAC to creatine kinase and ANT has the function to provide a high $\Delta G$ by transferring the ATP phosphoryl group to creatine.

Kinetic analysis of hexokinase isotype I binding to VDAC reconstituted in liposoms, isolated from outer mitochondrial membrane, and functionally intact mitochondria showed different binding behavior of hexokinase. The capacity and the binding kinetic varied dependent on the presence of contact sites with the mitochondrial inner membrane [73]. An increase of mitochondrial contact sites by dextran led to higher binding capacity and cooperative binding behavior in contrast to isolated outer membranes or mitochondria with contact sites reduced by glycerol or DNP [74]. Moreover, induction of contact sites by dextran resulted in a functional coupling of the bound hexokinase with oxidative phosphorylation. The more ATP was produced by the respiratory chain the more active was hexokinase and the enzymatic reactions of glycolysis. This was observed by following the stimulation of mitochondrial respiration by ADP produced through bound hexokinase. The respiration was studied in the presence of extra-mitochondrial pyruvate kinase and phosphorenol phosphate to consume external ADP. The ADP scavenging system was less effective after induction of contact sites by dextran [75]. Xie and Wilson found that hexokinase I forms tetramers by binding to the mitochondrial surface [76] and Hashimoto and Wilson analyzed the surface of bound hexokinase by using surface domain specific antibodies [77]. The authors observed that the bound hexokinase changed its structure according to the function of ANT and the rate of oxidative phosphorylation. This suggested a tight coupling between hexokinase and ANT transmitted by VDAC. The finding emphasizes the idea that the bound hexokinase has the function to adapt the rate of glycolysis to oxidative phosphorylation. In tumor cells this kind of regulation is missing (see below).

\section{Hexokinase-VDAC-ANT complexes in tumor cells}

Cancer cells are characterized by a high rate of glycolysis which serves as their primary energy-generating pathway [78]. The molecular basis of this high glycolysis activity involves a number of genetic and biochemical events, including over-expression of mitochondria-bound isoforms HK-I and HK-II [78]. It has been shown that cancer cells possess high 


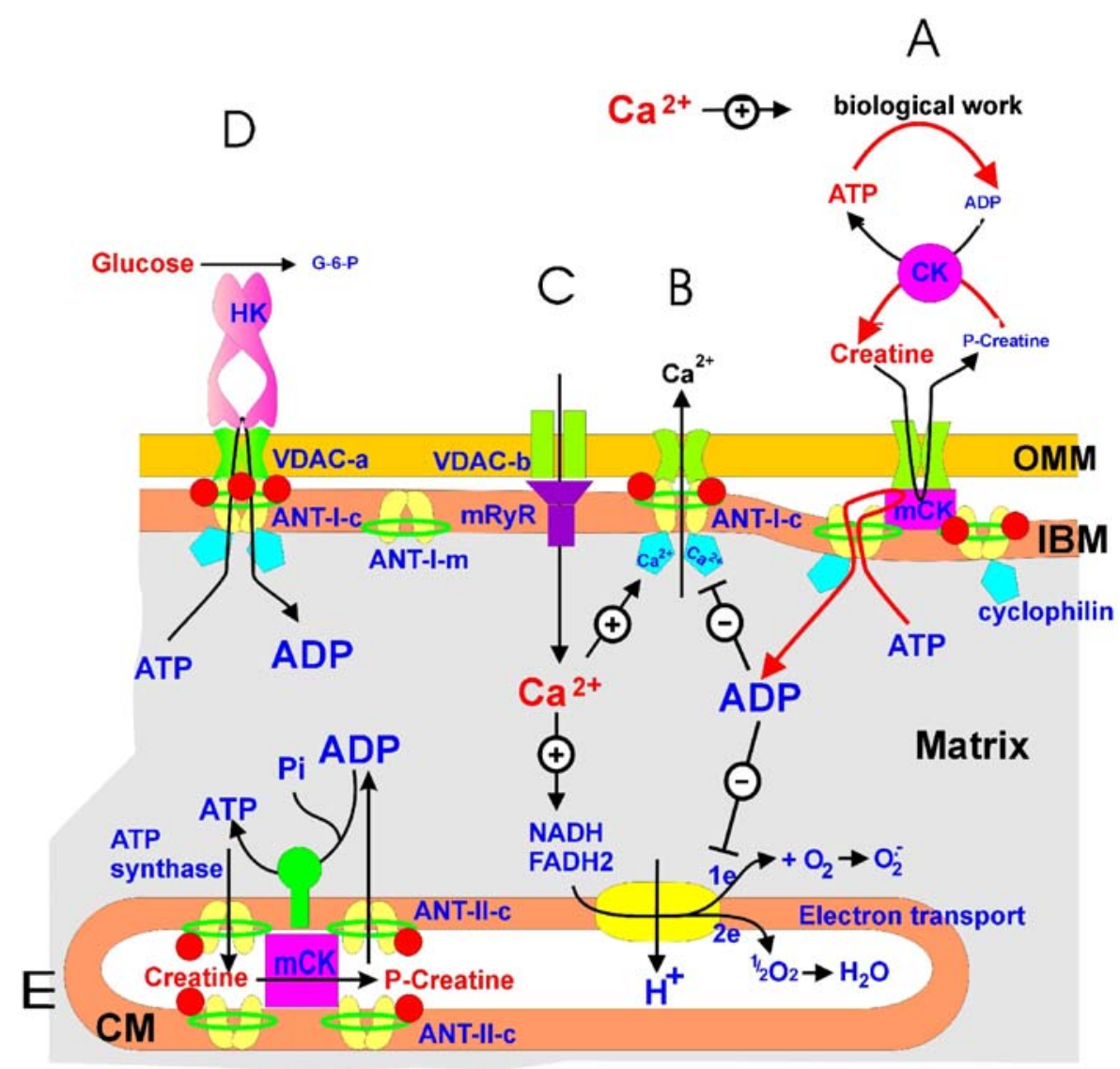

Fig. 2 Metabolite circuits involving the PT-pore. (A) Biological work (e.g. contraction) triggers cytosolic ADP-ATP turnover and leads to the increase of cytosolic creatine through activity of cytosolic creatine kinase (CK). Creatine causes an increase of intra-mitochondrial ADP by the activity of mitochondrial creatine kinase that is linked to the adenine nucleotide translocator (ANT) through cardiolipin (dark green rings). In a complex with CK ANT is acting as anti-porter in the inner membrane. (B) In absence of ADP and presence of high $\mathrm{Ca}^{2+}$, ANT can form an unspecific permeability transition pore (PTP) that releases $\mathrm{Ca}^{2+}$. (C) The mitochondrial ryanodine receptor mRyR may be liked to VDAC. $\mathrm{Ca}^{2+}$ activates substrate supply to the electron transport chain. This may lead to increased ROS formation if it is not accompanied by ADP increase. (D) In the hexokinase complex the enzyme forms a tetramer that is linked to two dimers of VDAC and ANT. In brain and

levels of HK activity and that drugs that detach HK from mitochondrial membranes decrease cell viability [79].

Specific for tumor cells is the glucose-induced inhibition of oxidative phosphorylation, known as the Crabtree effect [80]. It was suggested that mitochondrial oxidative phosphorylation lacks ADP because it is consumed by high activity of pyruvate kinase outside the mitochondria. This behavior is comparable to the ADP scavenge system described above that was artificially established to study the functional coupling of hexokinase to ANT. Thus, the Crabtree effect in tumor cells indicates that the functional coupling of hexokinase to ANT in the contact sites is missing. Indeed, by applying freeze fracture analysis it was observed that contact sites were absent in HT29 tumor cells that had a high heart mitochondria ANT isotype I is in this complex [68]. It is in its cconformation (ANT-I-c, induced by atractyloside), where it can operate either as anti-porter to exchange ATP for ADP or as uni-porter forming an unspecific pore. ANT in the m-conformation (ANT-m, induced by bongkrekate) does not form complexes with VDAC and cannot cause PTP. The oligomerization of hexokinase leads to activation of the enzyme. VDAC obtains a different structure by interaction with ANT in the c-conformation that has higher capacity to bind hexokinase. Both kinase complexes contain cytochrome $c$ represented by red dots. It is bound to cardiolipin (green ring) (E) ANT isotype II was found in the cristae together with the octamer of mitochondrial creatine kinase. This enzyme attaches specifically to the cardiolipin that is surrounding ANT-II. OMM: outer mitochondrial membrane, IBM: inner boundary membrane, CM: cristae membrane

glycolytic rate and displayed a typical Crabtree effect [81]. However, contact sites re-appeared and the Crabtree effect disappeared when the same cells were converted to normal cells by growing them in the absence of glucose. In this case oxidative phosphorylation was the only source of ATP and VDAC-ANT complexes were forming to facilitate ATP/ADP exchange.

\section{Hexokinase as a marker enzyme of contact sites}

Contact sites between outer mitochondrial and peripheral inner membrane were analyzed by freeze fracturing mitochondria and were found to be transient structures forming dependent on the activity of the oxidative phosphorylation 
[74]. ADP and atractyloside induced the contacts, while glycerol and DNP depressed them [82].

Hexokinase I could be localized by immune electron microscopy in the contacts between inner and outer boundary membrane. The enzyme was therefore used as a specific marker upon isolation of contact sites. Mitochondrial membranes were fragmented by osmotic shock. Centrifugation of the membrane fragments on a sucrose density gradient resulted in a fraction with high hexokinase activity and intermediate density that was distinct from outer (monoamino oxidase) and inner membrane (succinate dehydrogenase) marker enzymes. The contacts contained VDAC and ANT $[83,84]$ as determined by specific antibodies.

\section{VDAC-ANT Complexes}

The investigations described above suggested that complexes between VDAC and ANT are forming contact sites. This assumption was supported by the observation that a change of ANT structure resulted in an increase or decrease of contact sites [85]. Kidney mitochondria were pretreated either by atractyloside or bongkrekate and subjected to osmotic shock and contact site isolation by sucrose density centrifugation. Hexokinase activity as a marker for contact sites disappeared in the contact site fraction in the presence of bongkrekate while in the presence of atractyloside it increased to a higher level than compared to untreated mitochondria. The results supported the assumption raised above that VDAC-ANT complexes form contact sites to which hexokinase binds specifically. The contact site marker hexokinase was subsequently used to isolate VDAC and ANT complexes from a $1 \%$ Triton extract. Hexokinase in the Triton extract was bound to an anion exchanger column and was eluted by $\mathrm{KCl}$ gradient. The hexokinase activity peak contained a tetramer of hexokinase, VDAC, ANT and cyclophilin D [86, 87]. As observed with hexokinase, cyclophilin D bound to immobilized antibodies was used to isolate the VDAC-ANT complex from a Chaps extract of heart muscle mitochondria [88]. The hexokinase-VDAC-ANT complex as well as the cyclophilin-VDAC-ANT complex were reconstituted in liposomes and resembled the $\mathrm{Ca}^{2+}$ dependent, Cyclosporin $\mathrm{A}$ sensitive permeability transition pore.

\section{VDAC-ANT complexes contain cytochrome $c$}

Release of cytochrome $c$ from mitochondria is considered to be a key event in the apoptotic process, although the precise mechanism regulating cytochrome $c$ release remain unknown [89]. To date, all of the mitochondrial components known to translocate to the cytoplasm following an apoptotic stimulus reside in the mitochondrial inter-membrane space. Therefore, only the outer membrane needs to be modified. Indeed, some models suggest that the release exclusively involves an increase in outer membrane permeability due to the formation of a channel large enough to account for the release of proteins such as cytochrome $c$, while others consider its release due to a large-scale disruption of the outer membrane $[55,90,91]$. However, it has been observed that cytochrome $c$ can be released without rupture of the outer membrane and that contact sites are involved [91]. Approximately 20\% of the total cytochrome $c$ was found in the contacts site fraction in isolated kidney and brain mitochondria. This amount was increased upon induction of contact sites by pre-incubation with atractyloside or by addition of dextran whereas it was decreasing after depression of contact sites by pre-incubation with bongkrecate or treatment with glycerol or DNP [85]. It was already suggested above that tetramers of hexokinase preferentially bind to contact sites formed by VDAC-ANT interaction. Thus it may be assumed because of stoichiometric reasons that also tetramers of VDAC are present in the cytochrome $c$ containing contact sites (Fig. 3). Thus, these VDAC tetramers could constitute the channel for cytochrome $c$ release during apoptosis.

\section{VDAC oligomerization and cytochrome c binding}

Both soluble and membrane-embedded VDAC can assemble into dimers, trimers and tetramers as demonstrated by cross-linking with five cross-linking reagents bearing different spacer lengths (3-16 ̊) and membrane permeability [55]. VDAC assembly into oligomers is a dynamic process as demonstrated by FRET between purified VDAC labeled with either FITC or EITC [55].

The mechanisms of how cytochrome $c$ is organized in the contact sites remains elusive. Involvement of VDAC oligomerization in the release of cytochrome $c$ from mitochondria was recently suggested [55]. It was also demonstrated that VDAC oligomerization is encouraged in the presence of cytochrome $c$. In VDAC-reconstituted liposomes containing encapsulated cytochrome $c$, but not in VDAC liposomes free of cytochrome $c$, VDAC dimers, trimers, and tetramers were observed even without chemical cross-linking [55]. This suggests that cytochrome $c$ interacts preferentially with VDAC oligomers present in the contact sites where the peripheral inner membrane contributes cardiolipin known as specific binding site of cytochrome $c$.

\section{Cholesterol and cardiolipin influence VDAC structurelfunction}

Sterols have been associated with purified mitochondrial VDAC, such as ergosterol in $N$. crassa [92] and cholesterol in VDAC from bovine heart [48]. Sterols were found to be essential for proper insertion of VDAC into bilayer membranes, and cholesterol increases VDAC conductance [93]. It was assumed that sterols function to increase the 
Fig. 3 Structure of

VDAC-ANT complex in the contact site. (A) Two dimers of VDAC and ANT are connected by non bilayer cardiolipin arranged as inverted micelle according to [100] (shown in B) or as opening to the cytosol. This arrangement would explain how inner membrane cardiolipin (diphosphatidyl glycerol DPG) could come to the mitochondrial surface and cytochrome $c$ could be detached from its binding sites in the contact sites by external Bax without forming pores. Hexokinase binds to the four VDAC as a tetramer hindering access of Bax to the cytochrome $c$ binding sites A) ANT in the presence of $\mathrm{Ca}^{2+}$ and absence of ADP changes to the uni-porter structure forming an unspecific permeability transition pore. (B) ANT in the absence of $\mathrm{Ca}^{2+}$ and presence of ADP generated by hexokinase obtains the anti-porter structure specific for ATP and ADP exchange. (C) VDAC and ANT are not connected when the octamer of the mitochondrial creatine kinase binds to cardiolipin surrounding ANT and on the other side to VDAC. A non bilayer arrangement of cardiolipin as shown in A and B is not possible in the creatine kinase contact site
A
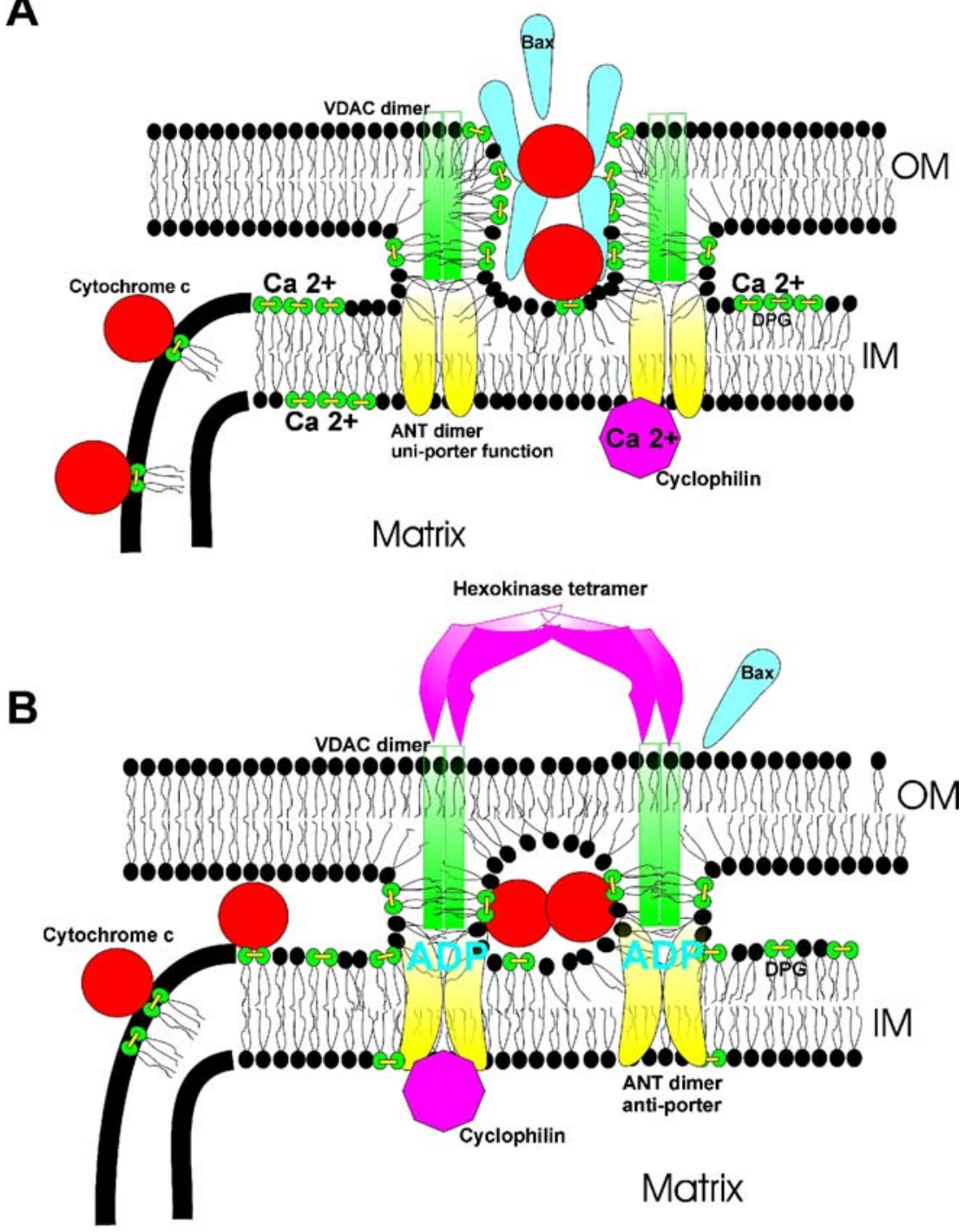

C

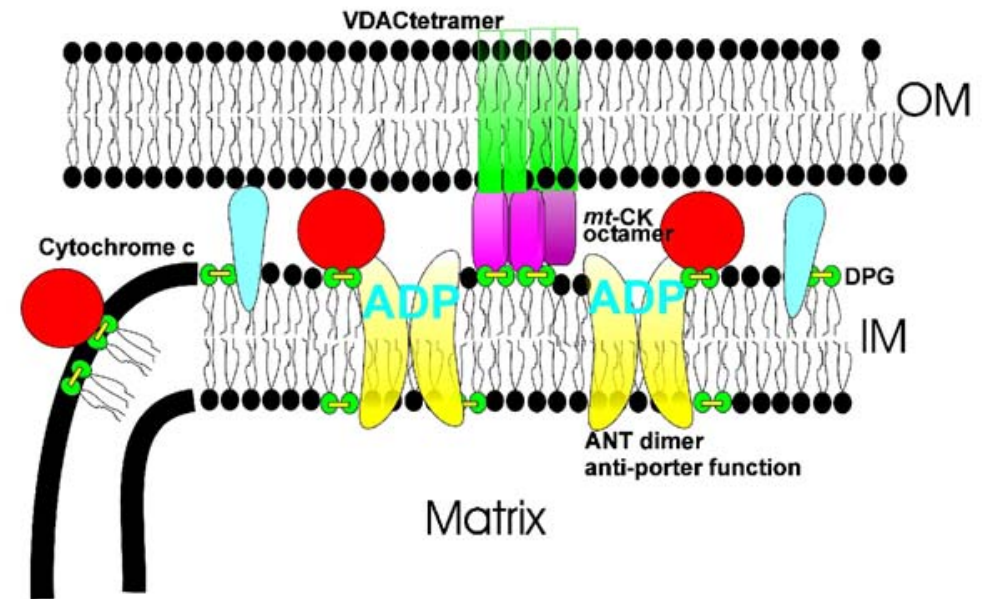


hydrophobicity of the VDAC $\beta$-barrel surface exposed to the phospholipid matrix of the membrane. The outer membrane contains $10 \%$ cholesterol, while almost none is found in the inner membrane [94]. The cholesterol in the outer membrane is non-randomly distributed [95] and VDAC is localised inside or outside the cholesterol-containing lipid raft-like areas [96]. This might explain the observed varying properties and structure of VDAC in different protein complexes. The hexokinase-VDAC-ANT complex has low cholesterol but high cardiolipin content compared to mean values of the membrane [97]. Interestingly, in certain tumour cells, a 3-fold higher cholesterol concentration was found and as described above contact sites were absent. The observed Crabtree effect suggested that VDAC-ANT complexes were missing [81], and this may explain suppression of apoptosis in tumour cells. Interestingly, treatment of tumour cells with inhibitors of cholesterol synthesis made them again susceptible for apoptosis [98].

Cardiolipin is a specific component of the inner membrane where it is tightly associated with several inner membrane proteins, controlling their activities. It may also indirectly regulate VDAC functions. VDAC forms contact sites with ANT containing tightly bound cardiolipin [99], and $\mathrm{Ca}^{2+}$ affects cardiolipin bound to ANT, thus regulating the interaction of VDAC with ANT. As cytochrome $c$ displays high affinity for cardiolipin it is concentrated in the contact sites as well [85]. A representation of the possible structure of the VDAC-ANT complex is shown in Fig. 3. According to the model of Van Venetie and Verkleij [100] cardiolipin may form inverted micelles or arrange in other non bilayer structures. The authors postulated formation of contact sites by pure non bilayer phospholipid arrangement induced by $\mathrm{Ca}^{2+}$. We postulate that cardiolipin may organise along the hydrophobic surface formed by the VDAC-ANT complex. This hydrophobic rod is penetrating the two boundary membranes when the two proteins interact. As depicted in Figs. 2 and 3 cytochrome $c$ can be arranged in the VDAC-ANT complex in a way that is accessible to external Bax and t-Bid.

There is evidence that cardiolipin is important in apoptosis induction [101] as specific binding site for cytochrome $c$ and pro-apoptotic proteins [102]. The cardiolipin exposed at the outer surface in the permeability transition pore, meaning the VDAC-ANT complex, appears to be the target for the proapoptotic protein Bax [103]. Bax may replace cytochrome $c$ from cardiolipin in the contacts and get incorporated into the VDAC ANT complex as shown in Fig. 3. Cardiolipin is also required for targeting t-Bid to mitochondria [104] where it appears to interact especially in the contact sites [105]. t-Bid perturbs the inner membrane and by that mobilizes cytochrome $c$ from the cristae surface to the mitochondrial inter-membranous space to facilitate its release [21].

\section{Novel insights}

\section{Additional components}

Evidence is accumulating that there are additional, unknown components of the PT-pore complex. A purification protocol led to a specific enrichment of proteins that could be resolved by two-dimensional electrophoresis [28]. Also, the analysis of cyclophilin D-interacting proteins revealed that several binding partners, besides ANT, exist [106]. A recent study described for the first time that a gluthatione-S-transferase interacts with ANT [107]. Interestingly, upon apoptosis induction this interaction is abolished indicating that this enzyme functions as an inhibitor of the PT-pore. Moreover, a number of additional interactors were identified, some of them localise to the endoplasmic reticulum, the cytosol and mitochondria. This indicates the complexity of the "ANT interactome" and the regulation of this protein aggregate.

\section{Genetic knock-outs}

\section{ANT knock-out studies}

The two ANT genes in mice were knocked out in hepatocytes [108]. This led to a number of secondary responses such as the upregulation of cyctochrome $c$, the down-regulation of the UCP2, the stimulation of the respiratory rate and an increased mitochondrial membrane potential. Experiments on the PT-pore revealed that its sensitivity for $\mathrm{Ca}^{2+}$ was reduced by a factor of three. Also, ANT ligands such as atractyloside and ADP had no modifying effect on the PT-pore anymore. However, the fact that PT could still be induced led the authors of the study to suggest that ANT is non-essential for the PT-pore [108]. Also, in ANT-deficient hepatocytes no altered apoptosis responses to the ligands of the Fas- and the TNF- receptor were observed. However, it is contentious $[109,110]$ whether the PT-pore in mitochondria is activated by these cell death signals that act at the plasma membrane and hence whether an altered apoptosis (and necrosis) response could have been expected. Furthermore, since this study was published another isoform of ANT (ANT4) has been discovered in the mouse genome [111]. So far its expression has only been detected in stem cells and testis but it might substitute for the inactivated genes in other tissues as well.

Nevertheless, the fact that the deletion of the two mouse ANT forms led to only a minor effect on the PT-pore was surprising and caused several different interpretations ranging from doubt that ANT-1/2-deficient tissues are indeed devoid of ANT activity (an argument supported by the recent discovery of ANT4, see above) to the notion that other carriers of this gene family might substitute for ANT [112]. These 
issues as well as the above described adaptive responses of the cells put into perspective the conclusion that ANT is dispensable for PT. Nevertheless, this publication led to a reappraisal of the role of the PT-pore components and the various interpretations can now be tested experimentally.

\section{Cyclophilin D knock-out studies}

Four groups published studies on cypD knock-out mice [113-116]. In these cypD-deficient animals the PT-pore cannot be activated by low concentrations of $\mathrm{Ca}^{2+}$. High concentrations of this ion such as $2 \mathrm{mM}$, however, still lead to PT [115] and cell death [113, 114]. A number of signals that cause apoptosis and/or necrosis such as t-Bid, Bax, etoposide, TNF- $\alpha$, and staurosporine had no different effect in cypD deficient mice. On the other hand, oxidative stress by $\mathrm{H}_{2} \mathrm{O}_{2}$ and $\mathrm{Ca}^{+2}$ increase by ionomycin and thapsigargin led to a different cell death induction as measured by the release of cytochrome $c$ [114] or PI staining [113]. One study [114] claims that cypD impacts only necrosis while another group also observed an effect on apoptosis induced by $\mathrm{H}_{2} \mathrm{O}_{2}$ as determined in a TUNEL- and an annexin V-assay [113]. It is known that signals too strong for cells to mount an active response cause the passive cell death of necrosis rather than the active suicide programme of apoptosis. Hence, the explanation for the discrepancy in the two studies might lie in the duration and strength of the stimulus used for cell death induction. However, it has to be stressed that the results presently available do not necessarily allow draw the conclusion that the PT-pore is not involved in apoptosis induction by some of the reagents tested. As with all knock-out experiments adaptive responses by the cells might obscure the effects.

\section{Overexpression studies on cypD}

One study suggests that overexpression of cypD in transgenic mice leads to apoptosis induction in the heart [113]. However, such effects can also be-as in knock-our experiments - the indirect consequence of a compensatory response during animal development [117]. Previous observations that cyclosporin A can repress PT-pore activation and apoptosis induction $[118,119]$ also suggested that cypD is acting in a pro-apoptotic way. However, a substantial body of evidence indicates that cypD has anti-apoptotic activities. Importantly, we [120,121] and others [122] have recently found that enforced cypD expression can specifically repress the activation of the PT-pore. Another study in neuronal cells also observed apoptosis inhibition (but sensitisation for necrosis) by cypD overexpression [123]. Moreover, there is accumulating evidence that cyclosporin A can induce apoptosis in certain cells [124-127]. In fact, the clinical use of CsA is still limited by its potential toxicity $[128,129]$ and a specific inhibition of the PT-pore as observed with cypD $[120,122]$ would be therapeutically of high interest. Hence, it is important to determine how overexpressed cypD induces or inhibits cell death. It has been suggested that cypD has more than one role in apoptosis and this might underlie these different activities [130]. Alternatively, cypD could have different targets in different cells. This could also explain why ANT-1/2 KO mice are still sensitive to CsA.

\section{A model of PT-pore activation}

When both ANT-1 and ANT-2 are absent $\mathrm{Ca}^{2+}$ could still induce the PT [108]. Also, in ANT1/2-negative cells, CsA could still further inhibit the $\mathrm{Ca}^{2+}$ sensitivity. This led us and others [117] to suggest that cypD has, besides ANT, additional and so far unknown interaction partners for PT and cell death. In fact, evidence is accumulating that there are novel components of the PT-pore complex (see above) $[28,107]$. Hence, for a thorough understanding of the PTpore it is of crucial importance to determine these interactors.

Novel studies have indicated that the composition of the PT-pore is not static but changes dependent on the physiological state of the cell. Hence, we propose that the PT-pore alters its composition during apoptosis and that anti-apoptotic factors are released and pro-apoptotic subunits recruited for apoptosis induction. The best evidence for this is currently available for hexokinase.

\section{Hexokinase inhibits cytochrome c release}

The structural change of VDAC achieved by interaction with ANT is recognized at the mitochondrial surface and leads to higher affinity of hexokinase. Recent observations suggest that this contact site structure is the preferred target of Bax molecules. Pastorino et al. [131] found that hexokinase and Bax compete for the same binding site of VDAC and Capano and Crompton [132] detected VDAC and ANT when Bax was immuno-precipitated from extracts of cardiomyocytes. The model depicted in Fig. 3 explains how Bax can get access to cardiolipin and cytochrome $c$ and hexokinase may hinder this. The binding of hexokinase to the contact sites is induced by protein kinase B (Akt) [133]. Activated protein kinase B can suppress apoptosis. The activity of mitochondrial bound hexokinase was found to be important for protein kinase Blinked suppression of cytochrome $c$ release and apoptosis [134].

When the hexokinase-VDAC-ANT complexes were isolated it was found they contained significant amount of cytochrome $c$ although the complex was eluted from anion exchanger column by $200 \mathrm{mM} \mathrm{KCl}$ suggesting that the cytochrome $c$ was not bound by ionic interaction. To investigate whether Bax would be able to interact with the cytochrome $c$ within the VDAC-ANT complexes, the latter 
were reconstituted in phospholipid vesicles. The vesicles were loaded with malate. Bax liberated the endogenous cytochrome $c$ but did not release the internal malate. The Bax dependent liberation of endogenous cytochrome $c$ was abolished when the VDAC-ANT complex was dissociated by bongkrekate or by stabilizing the hexokinase binding through addition of glucose. The internal malate could be released through opening the permeability transition pore by addition of $\mathrm{Ca}^{2+}$. This suggested that Bax did not form pores but released the cytochrome $c$ from specific binding sites in the VDAC-ANT complex (see Fig. 3) [85, 135].

In conclusion, the permeability transition in cell death is brought about by dynamic protein complexes that have the physiological function to regulate energy metabolism. These protein complexes change according to the needs of the cell and respond to different external and internal stimuli. During cell death the associations are altered in a way that cause the permeability transition in mitochondria. The basic components of the complexes are VDAC and ANT, functionally coupled to kinases such as hexokinase and creatine kinase. In tissues such as brain and heart this regulation involves specific isozymes of ANT. Thus, ANT-1 through its specific affinity to cyclophilin D plays an additional role in regulation of $\mathrm{Ca}^{2+}$ level, while ANT-2 trough its connection to mitochondrial creatine kinase is responsible in generating high $\Delta G$. We have tried to give an overview of the different aspects of the PT pore and hope that it has become apparent that this protein complex promises to yield many more exciting findings to fundamental questions on death and survival of cells. There is no doubt that the PT pore will continue to fascinate researchers in the future.

\section{References}

1. Bernardi P, Krauskopf A, Basso E et al (2006) The mitochondrial permeability transition from in vitro artifact to disease target. FEBS J 273:2077-2099

2. Kroemer G (1997) Mitochondrial implication in apoptosis. Towards an endosymbiont hypothesis of apoptosis evolution. Cell Death Differ 4:443-456

3. Kroemer G, Zamzami N, Susin SA (1997) Mitochondrial control of apoptosis. Immunol Today 18:44-51

4. Boise LH, Thompson CB (1997) Bcl-x(L) can inhibit apoptosis in cells that have undergone Fas-induced protease activation. Proc Natl Acad Sci USA 94:3759-3764

5. Miossec C, Dutilleul V, Fassy F, Diu-Hercend A (1997) Evidence for CPP32 activation in the absence of apoptosis during $\mathrm{T}$ lymphocyte stimulation. J Biol Chem 272:13459-13462

6. Lesage S, Steff AM, Philippoussis F et al (1997) CD4+ CD8+ thymocytes are preferentially induced to die following CD45 cross-linking, through a novel apoptotic pathway. J Immunol 159:4762-4771

7. Lavoie JN, Nguyen M, Marcellus RC, Branton PE, Shore GC (1998) E4orf4, a novel adenovirus death factor that induces p53-independent apoptosis by a pathway that is not inhibited by zVAD-fmk. J Cell Biol 140:637-645
8. He L, Lemasters JJ (2002) Regulated and unregulated mitochondrial permeability transition pores: a new paradigm of pore structure and function? FEBS Lett 512:1-7

9. Bernardi P, Scorrano L, Colonna R, Petronilli V, Di Lisa F (1999) Mitochondria and cell death. Mechanistic aspects and methodological issues. Eur J Biochem 264:687-701

10. Pastorino JG, Chen ST, Tafani M, Snyder JW, Farber JL (1998) The overexpression of Bax produces cell death upon induction of the mitochondrial permeability transition. J Biol Chem 273:7770-7775

11. Narita M, Shimizu S, Ito T et al (1998) Bax interacts with the permeability transition pore to induce permeability transition and cytochrome $c$ release in isolated mitochondria. Proc Natl Acad Sci USA 95:14681-14686

12. Marzo I, Brenner C, Zamzami N et al (1998) Bax and adenine nucleotide translocator cooperate in the mitochondrial control of apoptosis. Science 281:2027-2031

13. Zamzami N, Brenner C, Marzo I, Susin SA, Kroemer G (1998) Subcellular and submitochondrial mode of action of Bcl-2-like oncoproteins. Oncogene 16:2265-2282

14. Halestrap AP, Brenner C (2003) The adenine nucleotide translocase: a central component of the mitochondrial permeability transition pore and key player in cell death. Curr Med Chem 10:1507-1525

15. Brustovetsky N, Klingenberg M (1996) Mitochondrial ADP/ATP carrier can be reversibly converted into a large channel by $\mathrm{Ca}^{2+}$. Biochemistry 35:8483-8488

16. Martinou I, Desagher S, Eskes R et al (1999) The release of cytochrome $c$ from mitochondria during apoptosis of NGFdeprived sympathetic neurons is a reversible event. J Cell Biol 144:883-889

17. Jurgensmeier JM, Xie Z, Deveraux Q et al (1998) Bax directly induces release of cytochrome $c$ from isolated mitochondria. Proc Natl Acad Sci USA 95:4997-5002

18. Finucane DM, Bossy-Wetzel E, Waterhouse NJ, Cotter TG, Green DR (1999) Bax-induced caspase activation and apoptosis via cytochrome $c$ release from mitochondria is inhibitable by Bcl-xL. J Biol Chem 274:2225-2233

19. Kluck RM, Esposti MD, Perkins G et al (1999) The pro-apoptotic proteins, Bid and Bax, cause a limited permeabilization of the mitochondrial outer membrane that is enhanced by cytosol. $\mathrm{J}$ Cell Biol 147:809-822

20. Eskes R, Antonsson B, Osen-Sand A et al (1998) Bax-induced cytochrome $\mathrm{C}$ release from mitochondria is independent of the permeability transition pore but highly dependent on $\mathrm{Mg}^{2+}$ ions. J Cell Biol 143:217-224

21. Scorrano L, Ashiya M, Buttle K et al (2002) A distinct pathway remodels mitochondrial cristae and mobilizes cytochrome $c$ during apoptosis. Developmental Cell 2:55-67

22. Desagher S, Martinou JC (2000) Mitochondria as the central control point of apoptosis. Trends Cell Biol 10:369-377

23. Yang J, Liu X, Bhalla K et al (1997) Prevention of apoptosis by Bcl-2: release of cytochrome $c$ from mitochondria blocked. Science 275:1129-1132

24. Kluck RM, Bossy-Wetzel E, Green DR, Newmeyer DD (1997) The release of cytochrome $c$ from mitochondria: a primary site for Bcl-2 regulation of apoptosis. Science 275:1132-1136

25. Goldstein JC, Waterhouse NJ, Juin P, Evan GI, Green DR (2000) The coordinate release of cytochrome $c$ during apoptosis is rapid, complete and kinetically invariant. Nat Cell Biol 2:156-162

26. Bossy-Wetzel E, Newmeyer DD, Green DR (1998) Mitochondrial cytochrome $c$ release in apoptosis occurs upstream of DEVDspecific caspase activation and independently of mitochondrial transmembrane depolarization. EMBO J 17:37-49

27. Deshmukh M, Kuida K, Johnson EM Jr (2000) Caspase inhibition extends the commitment to neuronal death beyond cytochrome 
$c$ release to the point of mitochondrial depolarization. J Cell Biol 150:131-143

28. Marzo I, Brenner C, Zamzami N et al (1998) The permeability transition pore complex: a target for apoptosis regulation by caspases and bcl-2-related proteins. J Exp Med 187:1261-1271

29. Susin SA, Zamzami N, Castedo M et al (1997) The central executioner of apoptosis: multiple connections between protease activation and mitochondria in Fas/APO-1/CD95- and ceramide-induced apoptosis. J Exp Med 186:25-37

30. Pastorino JG, Tafani M, Rothman RJ et al (1999) Functional consequences of the sustained or transient activation by Bax of the mitochondrial permeability transition pore. J Biol Chem 274:31734-31739

31. Jouaville LS, Ichas F, Mazat JP (1998) Modulation of cell calcium signals by mitochondria. Mol Cell Biochem 184:371-376

32. Ichas F, Jouaville LS, Mazat JP (1997) Mitochondria are excitable organelles capable of generating and conveying electrical and calcium signals. Cell 89:1145-1153

33. Scorrano L, Ashiya M, Buttle K et al (2002) A distinct pathway remodels mitochondrial cristae and mobilizes cytochrome $c$ during apoptosis. Dev Cell 2:55-67

34. Leist M, Single B, Castoldi AF, Kuhnle S, Nicotera P (1997) Intracellular adenosine triphosphate (ATP) concentration: a switch in the decision between apoptosis and necrosis. J Exp Med 185:1481-1486

35. Crompton M, Costi A (1988) Kinetic evidence for a heart mitochondrial pore activated by $\mathrm{Ca}^{2+}$, inorganic phosphate and oxidative stress. A potential mechanism for mitochondrial dysfunction during cellular $\mathrm{Ca}^{2+}$ overload. Eur J Biochem 178:489-501

36. Crompton M (1999) The mitochondrial permeability transition pore and its role in cell death. Biochem J 341:233-249

37. Crompton M, Costi A (1990) A heart mitochondrial $\mathrm{Ca}^{2(+)}$ dependent pore of possible relevance to re-perfusion-induced injury. Evidence that ADP facilitates pore interconversion between the closed and open states. Biochem J 266:33-39

38. Jacobson J, Duchen MR (2002) Mitochondrial oxidative stress and cell death in astrocytes-requirement for stored $\mathrm{Ca}^{2+}$ and sustained opening of the permeability transition pore. J Cell Sci 115:1175-1188

39. Halestrap AP (1999) The mitochondrial permeability transition: its molecular mechanism and role in reperfusion injury. Biochem Soc Symp 66:181-203

40. Roos N, Benz R, Brdiczka D (1982) Identification and characterization of the pore-forming protein in the outer membrane of rat liver mitochondria. Biochim Biophys Acta 686:204-214

41. Benz R (1994) Permeation of hydrophilic solutes through mitochondrial outer membranes: Review on mitochondrial porins. Biochim Biophys Acta 1197:167-196

42. Tanveer A, Virji S, Andreeva L et al (1996) Involvement of cyclophilin $\mathrm{D}$ in the activation of a mitochondrial pore by $\mathrm{Ca}^{2+}$ and oxidant stress. Eur J Biochem 238:166-172

43. Debatin KM, Poncet D, Kroemer G (2002) Chemotherapy: targeting the mitochondrial cell death pathway. Oncogene 21:8786-8803

44. Beutner G, Ruck A, Riede B, Brdiczka D (1998) Complexes between porin, hexokinase, mitochondrial creatine kinase and adenylate translocator display properties of the permeability transition pore. Implication for regulation of permeability transition by the kinases. Biochim Biophys Acta 1368:7-18

45. De Pinto V, Prezioso G, Thinnes F, Link TA, Palmieri F (1991) Peptide-specific antibodies and proteases as probes of the transmembrane topology of the bovine heart mitochondrial porin. Biochemistry 30:10191-10200

46. Colombini M (2004) VDAC: the channel at the interface between mitochondria and the cytosol. Mol Cell Biochem 256-257:107-115
47. Reymann S, Thinnes F et al (1995) Further evidence for multitopological localization of mammalian porin (VDAC) in the plasmalemma forming part of a chloride channel complex affected in cystic fibrosis and encephalomyopathy. Biochem Mol Med 54:75-87

48. DePinto V, Benz R, Palmieri F (1989) Interaction of non-classical detergents with the mitochondrial porin. A new purification procedure and characterization of the pore-forming unit. Eur J Biochem 183:179-187

49. Thomas L, Blachly-Dyson E, Colombini M, Forte M (1993) Mapping of residues forming the voltage sensor of the voltagedependent anion-selective channel. Proc Natl Acad Sci USA 90:5446-5449

50. Song J, Midson C, Blachly-Dyson E, Forte M, Colombini M (1998) The topology of VDAC as probed by biotin modification. J Biol Chem 273:24406-24413

51. Rostovtseva TK, Liu TT, Colombini M, Parsegian VA, Bezrukov SM (2000) Positive cooperativity without domains or subunits in a monomeric membrane channel. Proc Natl Acad Sci USA 97:7819-7822

52. Krause J, Hay R, Kowollik C, Brdiczka D (1986) Cross-linking analysis of yeast mitochondrial outer membrane. Biochim Biophys Acta 860:690-698

53. Linden M, Gellerfors P (1983) Hydrodynamic properties of porin isolated from outer membranes of rat liver mitochondria. Biochim Biophys Acta 736:125-129

54. Shoshan-Barmatz V, Zalk R, Gincel D, Vardi N (2004) Subcellular localization of VDAC in mitochondria and ER in the cerebellum. Biochim Biophys Acta 1657:105-114

55. Zalk R, Israelson A, Garty ES, Azoulay-Zohar H, ShoshanBarmatz V (2005) Oligomeric states of the voltage-dependent anion channel and cytochrome $c$ release from mitochondria. Biochem J 386:73-83

56. Martin W, Hoffmeister M, Rotte C, Henze K (2001) An overview of endosymbiotic models for the origins of eukaryotes, their ATP-producing organelles (mitochondria and hydrogenosomes), and their heterotrophic lifestyle. Biol Chem 382:1521-1539

57. Gumaa KA, McLean P, Greenbaum AL (1971) Compartmentation in relation to metabolic control in liver. Essays Biochem 7:39-86

58. Wallimann T, Wyss M, Brdiczka D, Nicolay K, Eppenberger HM (1992) Intracellular compartmentation, structure and function of creatine kinase isoenzymes in tissues with high and fluctuating energy demands: the 'phosphocreatine circuit' for cellular energy homeostasis. Biochem J 281:21-40

59. Saks V, Dzeja P, Schlattner U et al (2006) Cardiac system bioenergetics: metabolic basis of the Frank-Starling law. J Physiol 571:253-273

60. Bernardi P, Azzone GF (1981) Cytochrome $c$ as an electron shuttle between the outer and inner mitochondrial membranes. J Biol Chem 256:7187-7192

61. Marzulli D, La Piana G, Franseve E, Lofrumento NE (1999) Modulation of cytochrome c- mediated extramitochondrial NADH oxidation by contact site structure. Biochem Biophys Res Commun 259:325-330

62. Brdiczka D, Zorov DB, Sheu SS (2006) Mitochondrial contact sites: their role in energy metabolism and apoptosis. Biochim Biophys Acta 1762:148-163

63. Schein SJ, Colombini M, Finkelstein A (1976) Reconstitution in planar lipid bilayers of a voltage-dependent anion-selective channel obtained from paramecium mitochondria. J Membr Biol 30:99-120

64. Ruck A, Dolder M, Wallimann T, Brdiczka D (1998) Reconstituted adenine nucleotide translocase forms a channel for small molecules comparable to the mitochondrial permeability transition pore. FEBS Lett 426:97-101 
65. Crompton M, Virji S, Ward JM (1998) Cyclophilin-D binds strongly to complexes of the voltage-dependent anion channel and the adenine nucleotide translocase to form the permeability transition pore. Eur J Biochem 258:729-735

66. Woodfield K, Ruck A, Brdiczka D, Halestrap AP (1998) Direct demonstration of a specific interaction between cyclophilin-D and the adenine nucleotide translocase confirms their role in the mitochondrial permeability transition. Biochem J 336:287-290

67. Schlatter D, Thoma R, Kung E et al (2005) Crystal engineering yields crystals of cyclophilin D diffracting to 1.7 A resolution. Acta Crystallogr D Biol Crystallogr 61:513-519. Epub 2005 April 20

68. Vyssokikh MY, Katz A, Rück A et al (2001) Adenine nucleotide translocator isoforms 1 and 2 are differently distributed in the mitochondrial inner membrane and have distinct affinities to cyclophilin D. Biochem J 358:349-358

69. Fiek C, Benz R, Roos N, Brdiczka D (1982) Evidence for identity between the hexokinase-binding protein and the mitochondrial porin in the outer membrane of rat liver mitochondria. Biochim Biophys Acta 688:429-440

70. Lindén M, Gellerfors P, Nelson BD (1982) Pore protein and the hexokinase-binding protein from the outer membrane of rat liver mitochondria are identical. FEBS-Letters 141:189-192

71. Brdiczka D, Kaldis P, Wallimann T (1994) In vitro complex formation between octamer of creatine kinase and porin. J Biol Chem 269:27640-27644

72. Wilson JE (1978) Ambiquitous enzymes: variation in intracellular distribution as a regulatory mechanism. Trends Biochem Sci 3:124-125

73. Wicker U, Bücheler K, Gellerich FN et al (1993) Effect of macromolecules on the structure of the mitochondrial inter-membrane space and the regulation of hexokinase. Biochim Biophys Acta 1142:228-239

74. Knoll G, Brdiczka D (1983) Changes in freeze-fracture mitochondrial membranes correlated to their energetic state. Biochim Biophys Acta 733:102-110

75. Laterveer FD, Gellerich FN, Nicolay K (1995) Macromolecules increase the channeling of ADP from externally associated hexokinase to the matrix of mitochondria. Eur J Biochem 232:569-577

76. Xie G, Wilson JE (1990) Tetrameric structure of mitochondrially bound rat brain hexokinase: a crossliking study. Arch Biochem Biophys 276:285-293

77. Hashimoto M, Wilson JE (2000) Membrane potential-dependent conformational changes in mitochondrially bound hexokinase in brain. Arch Biochem Biophys 884:163-173

78. Pedersen PL, Mathupala S, Rempel A, Geschwind JF, Ko YH (2002) Mitochondrial bound type II hexokinase: a key player in the growth and survival of many cancers and an ideal prospect for therapeutic intervention. Biochim Biophys Acta 1555:14-20

79. Penso J, Beitner R (1998) Clotrimazole and bifonazole detach hexokinase from mitochondria of melanoma cells. Eur $\mathrm{J}$ Pharmacol 342:113-117

80. Ibsen HK (1961) The Crabtree effect: a review. Cancer Res 21:829-841

81. Denis-Pouxviel C, Riesinger I, Bühler C, Brdiczka D, Murat J-C (1987) Regulation of mitochondrial hexokinase in cultured HT 29 human cancer cells. Biochim Biophys Acta 902:335-348

82. Bücheler K, Adams V, Brdiczka D (1991) Localization of the ATP/ADP translocator in the inner membrane and regulation of contact sites between mitochondrial envelope membranes by ADP. A study on freeze fractured isolated liver mitochondria. Biochim Biophys Acta 1061:215-225

83. Ohlendieck K, Riesinger I, Adams V, Krause J, Brdiczka D (1986) Enrichment and biochemical characterization of boundary membrane contact sites from rat-liver mitochondria. Biochim Biophys Acta 860:672-689
84. Adams V, Bosch W, Schlegel J, Wallimann T, Brdiczka D (1989) Further characterization of contact sites from mitochondria of different tissues: toplogy of peripheral kinases. Biochim Biophys Acta 981:213-225

85. Vyssokikh MY, Zorova L, Zorov D et al (2004) The intramitochondrial cytochrome $c$ distribution varies correlated to the formation of a complex between VDAC and the adenine nucleotide translocase: this affects Bax-dependent cytochrome $c$ release. Biochim Biophys Acta 1644:27-36

86. Beutner G, Rück A, Riede B, Welte W, Brdiczka D (1996) Complexes between kinases, mitochondrial porin and adenylate translocator in rat brain resemble the permeability transition pore. FEBS Lett 396:189-195

87. Beutner G, Ruck A, Riede B, Brdiczka D (1997) Complexes between hexokinase, mitochondrial porin and adenylate translocator in brain: regulation of hexokinase, oxidative phosphorylation and permeability transition pore. Biochem Soc Trans 25:151-157

88. Crompton M, Virji S, Ward JM (1998) Cyclophilin-D binds strongly to complexes of the voltage-dependent anion channel and the adenine nucleotide translocase to form the permeability transition pore. Eur J Biochem 258:729-735

89. Liu X, Kim CN, Yang J, Jemmerson R, Wang X (1996) Induction of apoptotic program in cell-free extracts: requirement for dATP and cytochrome $c$. Cell 86:147-157

90. Martinou JC, Desagher S, Antonsson B (2000) Cytochrome $c$ release from mitochondria: all or nothing. Nat Cell Biol 2:E41E43

91. Doran E, Halestrap AP (2000) Cytochrome $c$ release from isolated rat liver mitochondria can occur independently of outer-membrane rupture: possible role of contact sites. Biochem $\mathrm{J}: 343-350$

92. Freitag H, Neupert W, Benz R (1982) Purification and characterization of a pore protein of the outer mitochondrial membrane from Neurospora crassa. Eur J Biochem 162:629-636

93. Popp B, Schmid A, Benz R (1995) Role of sterols in the functional reconstitution of water-soluble mitochondrial porins from different organisms. Biochemistry 34:3352-3361

94. Daum G (1985) Lipids of mitochondria. Biochim Biophys Acta 822:1-42

95. Ardail D, Privat J-P, Egret-Charlier M et al (1990) Mitochondrial contact sites, lipid composition and dynamics. J Biol Chem 265:18797-18802

96. Simons K, Ikonen E (1997) Functional rafts in cell membranes. Nature 387:569-572

97. Vyssokikh M, Brdiczka D (2004) Function of the outer mitochondrial membrane pore (Voltage-dependent Anion Channel) in intracellular signaling. In: Benz R (ed) Bacterial and eukaryotic porins structure, function, mechanism, Wiley-VCH, Weinheim Germany, pp 339-358

98. Dimitroulakos J, Nohynek D, Backway KL et al (1999) Increased sensitivity of acute myeloid leukemias to lovastatin-induced apoptosis: a potential therapeutic approach. Blood 93:1308 1318

99. Beyer K, Klingenberg M (1985) ADP/ATP carrier protein from beef heart mitochondria has high amounts of tightly bound cardiolipin, as revealed by $31 \mathrm{P}$ nuclear magnetic resonance. Biochemistry 24:3821-3826

100. Van Venetie R, Verkleij AJ (1982) Possible role of non-bilayer lipids in the structure of mitochondria. A freeze-fracture electron microscopy study. Biochim Biophys Acta 692:397-405

101. Newmeyer DD, Ferguson-Miller S (2003) Mitochondria: releasing power for life and unleashing the machineries of death. Cell 112:481-490

102. Iverson SL, Orrenius S (2004) The cardiolipin-cytochrome $c$ interaction and the mitochondrial regulation of apoptosis. Arch Biochem Biophys 423:37-46 
103. De Giorgi F, Lartigue L, Bauer MKA et al. The permeability transition pore signals apoptosis by directing Bax translocation and multimerization. FASEB J 16:607-609

104. Lutter M, Fang M, Luo X et al (2000) Cardiolipin provides specificity for targeting of tBid to mitochondria. Nat Cell Biol 2:754-761

105. Kim TH, Zhao Y, Ding WX et al (2004) Bid-Cardiolipin interaction at mitochondrial contact site contributes to mitochondrial cristae reorganization and cytochrome $c$ release. Mol Biol Cell 15:3061-3072

106. Woodfield K, Ruck A, Brdiczka D, Halestrap AP (1998) Direct demonstration of a specific interaction between cyclophilin-D and the adenine nucleotide translocase confirms their role in the mitochondrial permeability transition. Biochem J 336:287290

107. Verrier F, Deniaud A, Lebras M et al (2004) Dynamic evolution of the adenine nucleotide translocase interactome during chemotherapy-induced apoptosis. Oncogene 23:80498064

108. Kokoszka JE, Waymire KG, Levy SE et al (2004) The ADP/ATP translocator is not essential for the mitochondrial permeability transition pore. Nature 427:461-465

109. Kim TH, Zhao Y, Barber MJ, Kuharsky DK, Yin XM (2000) Bid-induced cytochrome $c$ release is mediated by a pathway independent of mitochondrial permeability transition pore and Bax. J Biol Chem 275:39474-39481

110. Soriano ME, Nicolosi L, Bernardi P (2004) Desensitization of the permeability transition pore by cyclosporin a prevents activation of the mitochondrial apoptotic pathway and liver damage by tumor necrosis factor-alpha. J Biol Chem 279:36803-36808. Epub 2004 Jun 16

111. Rodic N, Oka M, Hamazaki T et al (2005) DNA methylation is required for silencing of ant 4 , an adenine nucleotide translocase selectively expressed in mouse embryonic stem cells and germ cells. Stem Cells 23:1314-1323. Epub 2005 July 28

112. Halestrap AP (2004) Mitochondrial permeability: dual role for the ADP/ATP translocator? Nature 430:1 p following 983

113. Baines CP, Kaiser RA, Purcell NH et al (2005) Loss of cyclophilin D reveals a critical role for mitochondrial permeability transition in cell death. Nature 434:658-662

114. Nakagawa T, Shimizu S, Watanabe T et al (2005) Cyclophilin D-dependent mitochondrial permeability transition regulates some necrotic but not apoptotic cell death. Nature 434:652658

115. Basso E, Fante L, Fowlkes J et al (2005) Properties of the permeability transition pore in mitochondria devoid of Cyclophilin D. J Biol Chem 280:18558-18561. Epub 2005 March 25

116. Schinzel AC, Takeuchi O, Huang Z et al (2005) Cyclophilin $\mathrm{D}$ is a component of mitochondrial permeability transition and mediates neuronal cell death after focal cerebral ischemia. Proc Natl Acad Sci USA 102:12005-12010. Epub 2005 Aug 15

117. Forte M, Bernardi P (2005) Genetic dissection of the permeability transition pore. J Bioenerg Biomembr 37:121-128

118. Halestrap AP, Davidson AM (1990) Inhibition of $\mathrm{Ca}^{2(+)}$-induced large-amplitude swelling of liver and heart mitochondria by cyclosporin is probably caused by the inhibitor binding to mitochondrial-matrix peptidyl-prolyl cis-trans isomerase and preventing it interacting with the adenine nucleotide translocase. Biochem J 268:153-160
119. McGuinness O, Yafei N, Costi A, Crompton M (1990) The presence of two classes of high-affinity cyclosporin A binding sites in mitochondria. Evidence that the minor component is involved in the opening of an inner-membrane $\mathrm{Ca}^{(2+)}$-dependent pore. Eur J Biochem 194:671-679

120. Schubert A, Grimm S, Cyclophilin D (2004) A Component of the Permeability Transition (PT)-Pore, Is an Apoptosis Repressor. Cancer Res 64:85-93

121. Bauer MKA, Schubert A, Rocks O, Grimm S (1999) Adenine nucleotide translocase-1, a component of the permeability transition pore, can dominantly induce apoptosis. J Cell Biol 147:1493-1502

122. Lin DT, Lechleiter JD (2002) Mitochondrial targeted cyclophilin d protects cells from cell death by peptidyl prolyl isomerization. J Biol Chem 277:31134-31141

123. Li Y, Johnson N, Capano M, Edwards M, Crompton M (2004) Cyclophilin-D promotes the mitochondrial permeability transition but has opposite effects on apoptosis and necrosis. Biochem J 383:101-109

124. Esposito C, Fornoni A, Cornacchia F et al (2000) Cyclosporine induces different responses in human epithelial, endothelial and fibroblast cell cultures. Kidney Int 58:123-130

125. Gottschalk AR, Boise LH, Thompson CB, Quintans J (1994) Identification of immunosuppressant-induced apoptosis in a murine B-cell line and its prevention by Bcl-x but not bcl-2. Proc Natl Acad Sci USA 91:7350-7354

126. Damoiseaux JG, Defresne MP, Reutelingsperger CP, Van Breda Vriesman PJ (2002) Cyclosporin-A differentially affects apoptosis during in vivo rat thymocyte maturation. Scand J Immunol 56:353-360

127. Grub S, Persohn E, Trommer WE, Wolf A (2000) Mechanisms of cyclosporine A-induced apoptosis in rat hepatocyte primary cultures. Toxicol Appl Pharmacol 163:209-220

128. Serkova NJ, Christians U, Benet LZ (2004) Biochemical mechanisms of cyclosporine neurotoxicity. Mol Interv 4:97-107

129. Waldmeier PC, Feldtrauer JJ, Qian T, Lemasters JJ (2002) Inhibition of the mitochondrial permeability transition by the nonimmunosuppressive cyclosporin derivative NIM811. Mol Pharmacol 62:22-29

130. Crompton M (2003) On the involvement of mitochondrial intermembrane junctional complexes in apoptosis. Curr Med Chem 10:1473-1484

131. Pastorino JG, Shulga N, Hoek JB (2002) Mitochondrial binding of hexokinase II inhibits bax-induced cytochrome $c$ release and apoptosis. J. Biol. Chem. 277:7610-7618

132. Capano M, Crompton M (2002) Biphasic translocation of BAX to mitochondria. Biochem J 367:169-178

133. Gottlob K, Majewski N, Kennedy S et al (2001) Inhibition of early apoptotic events by $\mathrm{Akt} / \mathrm{PKB}$ is dependent on the first committed step of glycolysis and mitochondrial hexokinase. Genes Dev 15:1406-1418

134. Majewski N, Nogueira V, Bhaskar P et al (2004) Hexokinasemitochondria interaction mediated by Akt is required to inhibit apoptosis in the presence or absence of Bax and Bak. Mol Cell $16: 819-830$

135. Vyssokikh MY, Zorova L, Zorov D et al (2002) Bax releases cytochrome $c$ preferentially from a complex between porin and adenine nucleotide translocator. Hexokinase activity suppresses this effect. Mol Biol Rep 29:93-96 